UCRL-JC-121680

PREPRINT

\title{
Characterization of Static-and Fatigue-Loaded Carbon Composites by X-Ray CT
}

\author{
V. Savona \\ H. E. Martz \\ H. R. Brand \\ S. E. Groves \\ S. J. DeTeresa
}

This paper was prepared for submittal to the 22 Quantitative Non-destructive Evaluation Conference

Seattle, WA

July 30-A ugust 4, 1995

August 31, 1995

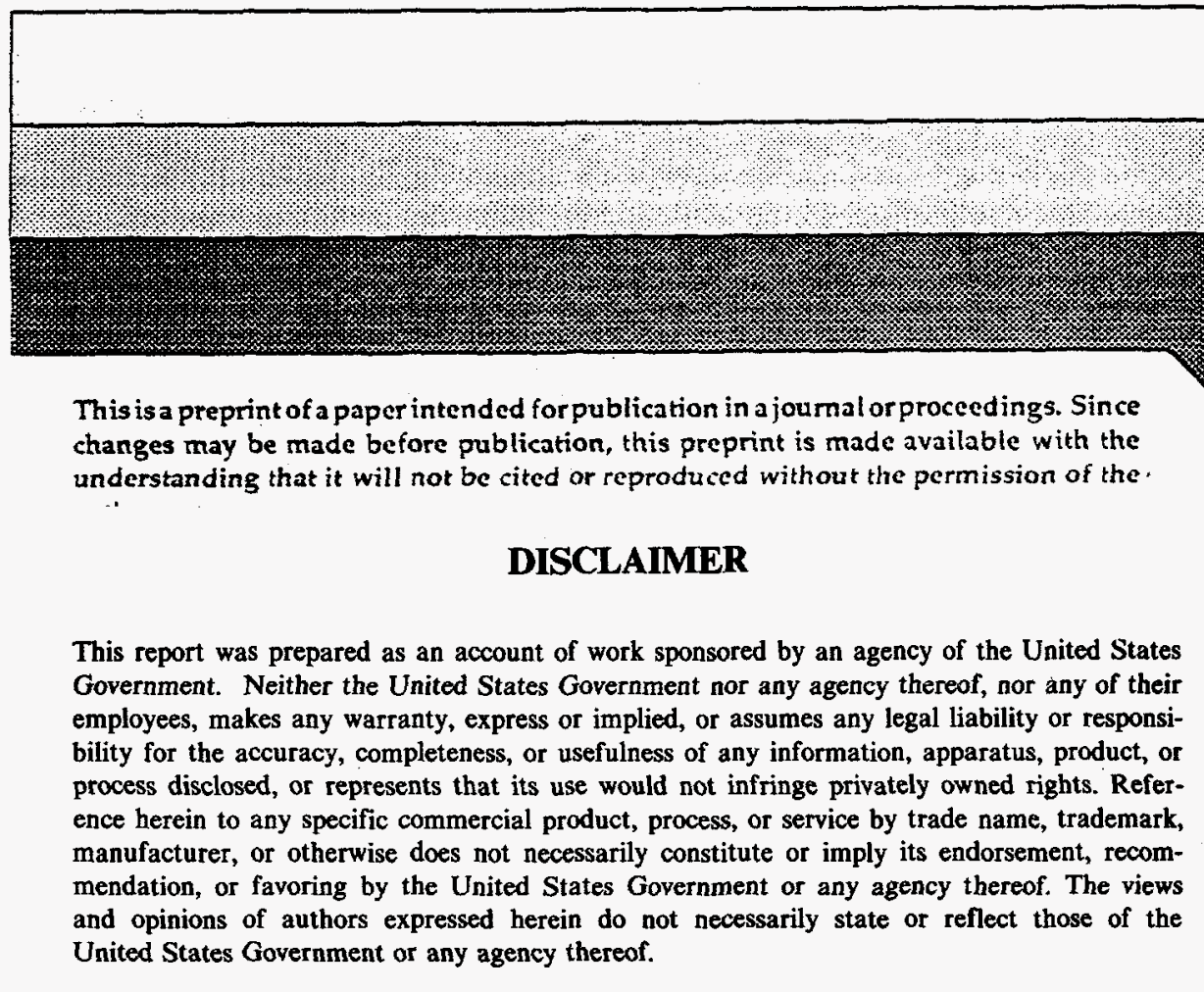




\section{DISCLAIMER}

This document was prepared as an account of work sponsored by an agency of the United States Covernment. Neither the United States Covernment nor the University of California nor any of their employces, makes any warranty, express or implied, or assumes any legal liability or responsibility for the accuracy, completeness, or uscfulness of any information, apparatus, product, or process disclosed, or represents that its use would not infringe privately owned rights. Reference hercin to any specific commercial product, process, or service by trade name, trademark, manufacturer, or otherwise, does not necessarily constitute or imply its endorsement, recommendation, or favoring by the United States Covernment or the University of California. The views and opinions of authors expressed hercin do not necessarilv state or reflect those of the United States Government or the University of California, and shall not be used for advertising or product endorsement purposes. 


\section{DISCLAIMER}

Portions of this document may be illegible in electronic image products. Images are produced from the best available original document. 


\title{
CHARACTERIZATION OF STATIC- AND FATIGUE-LOADED CARBON
}

\author{
COMPOSITES BY X-RAY CT* \\ Valentina Savona, ${ }^{* *}$ Harry E. Martz, Hal R. Brand, \\ Scott E. Groves and Steven J. DeTeresa \\ Lawrence Livermore National Laboratory \\ P.O. Box 808, L-333 \\ Livermore, CA 94551
}

\begin{abstract}
The development and improvement of advanced materials is strictly connected to the understanding of the properties and behavior of such materials as a function of both their macro- and micro-structures. The application of X-ray computed tomography (CT) to these materials allows for a better understanding of the materials properties and behavior on either macro- or micro-structure scales. We applied CT to study a set of aerospace grade carbon fiber/thermoplastic matrix composites. Samples of APC-2 (PEEK/AS4) were subjected to either static or high-stress fatigue loading in tension. Both notched (central circular hole) and unnotched specimens were examined. We are investigating a hightemperature thermoplastic polyimide composite sample by acquiring CT data sets before, during (at set intervals), and after full-reversal (tension-compression), low-stress fatigue loading at the upper use temperature. The CT scanner employed and the results obtained in the analysis of $3 \mathrm{D} C \mathrm{CT}$ data sets to study the defects and other features within the different composites are presented in this report.
\end{abstract}

\section{INTRODUCTION}

Computed Tomography methodologies were investigated to better understanding their possibility to improve the knowledge and a correct understanding of the behavior of thin Carbon-Polymer composites when static or fatigue loaded to failure.

The main goal of this work was to demonstrate the feasibility of using Computed Tomography to characterize the internal defects and microstructural damages for such materials. Our tasks included studying the typical load size composite specimens (on the order of $20 \times 2 \times 200 \mathrm{~mm}$ ), identifying the optimum scan parameter values for these samples, to correlate the defects with the corresponding loading situation in order to evaluate the agreement of the real data with the mechanical models of failure proposed in previous studies [1-3].

\section{MATERIAL DESCRIPTION}

The samples used for this study are Graphite-Epoxy [3], Graphite-Peek [2] and Graphite Polyimide[1] composites. A list of the samples and their material, geometric and loading characteristics are included in Tables 1-3, respectively.

* Work performed under auspices of the U.S. Department of Energy by the Lawrence Livermore National Laboratory under contract No. W-7405-ENG-48.

** Permanent address: Dipartimento di Ingegneria Meccanica, Università di Cagliari (ttaly). 
TABLE 1 Material Characteristics

\begin{tabular}{|c|c|c|c|c|}
\hline Name & CT Scan Session & Fiber-Matrix & Layers Sequence & $\begin{array}{c}\text { Density } \\
(\mathrm{g} / \mathrm{cc})\end{array}$ \\
\hline SU7/2/P10 & SS-A & Graphite-Epoxy & {$[ \pm 45 / 0 / 90] 4 \mathrm{~s}$} & $\sim 1.6$ \\
\hline P35P.20 & SS-B & Graphite-Peek & {$[ \pm 35] 4 \mathrm{~s}$} & $\sim 1.6$ \\
\hline QIBH.9 & SS-C & Graphite-Peek & {$[ \pm 45 / 0 / 90] 2 \mathrm{~s}$} & $\sim 1.6$ \\
\hline P15H.11 & SS-C & Graphite-Peek & {$[ \pm 15] 4 \mathrm{~s}$} & $\sim 1.6$ \\
\hline SU7/1/A & SS-C & Graphite-Epoxy & {$[ \pm 45 / 0 / 90] 4 \mathrm{~s}$} & $\sim 1.6$ \\
\hline QPS1 & SS-D & Graphite-Polyimide & {$[+45 / 90 /-45 / 0] 2 \mathrm{~s}$} & 1.6 \\
\hline
\end{tabular}

TABLE 2 Geometric Characteristics

\begin{tabular}{|c|c|c|c|c|}
\hline Name & $\begin{array}{c}\text { Geometric } \\
\text { characteristics }\end{array}$ & $\begin{array}{c}\text { Geometric cross } \\
\text { section size }(\mathrm{mm})\end{array}$ & $\begin{array}{c}\text { Hole } \\
\text { Diameter }(\mathrm{mm})\end{array}$ & $\begin{array}{c}\text { Scan } \\
\text { Aspect Ratio }\end{array}$ \\
\hline SU7/2/P10 & unnotched & $20 \times 2.2$ & NA & $\sim 4.5$ \\
\hline P35P.20 & unnotched & $20 \times 2.2$ & NA & $\sim 9$ \\
\hline QIBH.9 & circular hole & $50 \times 2.2$ & 8 & $\sim 7.6$ \\
\hline P15H.11 & circular hole & $50 \times 2.2$ & 8 & $\sim 7.6$ \\
\hline SU7/1/A & circular hole & $50 \times 2.2$ & 8 & -7.6 \\
\hline QPS1 & unnotched & $25.4 \times 2.286$ & NA & -5.5 \\
\hline
\end{tabular}

TABLE 3 Loading Characteristics

\begin{tabular}{|c|c|c|c|c|}
\hline Name & Loading Test & $\begin{array}{c}\text { Total number } \\
\text { of cycles }\end{array}$ & $\begin{array}{c}\sigma \max \\
\% \text { fract. load }\end{array}$ & $\begin{array}{c}\text { Temperature } \\
\text { ( } \mathrm{C})\end{array}$ \\
\hline SU7/2/P10 & static/tens-tens & & & 20 \\
\hline P35P.20 & fatigue/tens-tens & 7000 & 65 & 20 \\
\hline QIBH.9 & fatigue/tens-tens & 277000 & 70 & 20 \\
\hline P15H.11 & fatigue/tens-tens & 500000 & 88 & 20 \\
\hline SU7/1/A & fatigue/tens-tens & 750000 & 80 & 20 \\
\hline QPS1 & fatigue/tens-comp & 961401 & 0.2 & 180 \\
\hline
\end{tabular}

The CT study for all the Epoxy and PEEK samples occurred after the loading tests done at the University of Cagliari. The Graphite-Polyimide sample was studied before and after four tensile-compression low-stress fatigue loading tests at LLNL. CT data after loading were acquired every $0.2 \mathrm{Mcycles}$ at $180^{\circ} \mathrm{C}$. The fourth loading test was interrupted before completing its 0.2 Mcycles (total load of 961401 cycles) because excess deformation due to reduction in sample stiffness, exceeded $0.02 \mathrm{~mm}$.

\section{CT ACQUISITION SYSTEM}

The CT scanner used in this study, called PCAT, is a area-array (2D) rotate only (third generation) system. It basically consists of a $450 \mathrm{kVp} x$-ray machine source manufactured by Phillips and a detector system that couples a thermoelectrically cooled Photometrics Astronomy grade CCD camera to a high-density scintillating glass by a photographic lens. A schematic of PCAT is shown in Fig. 1. The PCAT staging consists of three degrees of freedom: rotational, and $x$ - and $y$-translations. These are mounted on a computed-controlled system that provides the movements along all three axes remotely. PCAT uses a Sun 3/260 workstation for data acquisition. Data preprocessing, image reconstruction and analysis are typically done on another Sun or Silicon Graphics computer (for this specific study we used a Silicon Graphics ONYX machine).

PCAT was used to acquire CT projections or Digital Radiographs (DR). It was configured to obtain a reconstructed pixel size of about $60.5 \mu \mathrm{m}$ for the Peek and Epoxy samples and about $41.7 \mu \mathrm{m}$ for the Polyimide one. In order to have the $41.7-\mu \mathrm{m}$ pixel size we needed to acquire two different CT scans to image most of the height of the sample (about $200 \mathrm{~mm}$ ) for each load situation. All data were acquired at $100-\mathrm{kVp}$ peak energy and 9-mA current, over a range of $180^{\circ}$; each scan session includes 360 equispaced projections in form of digital radiographs. 


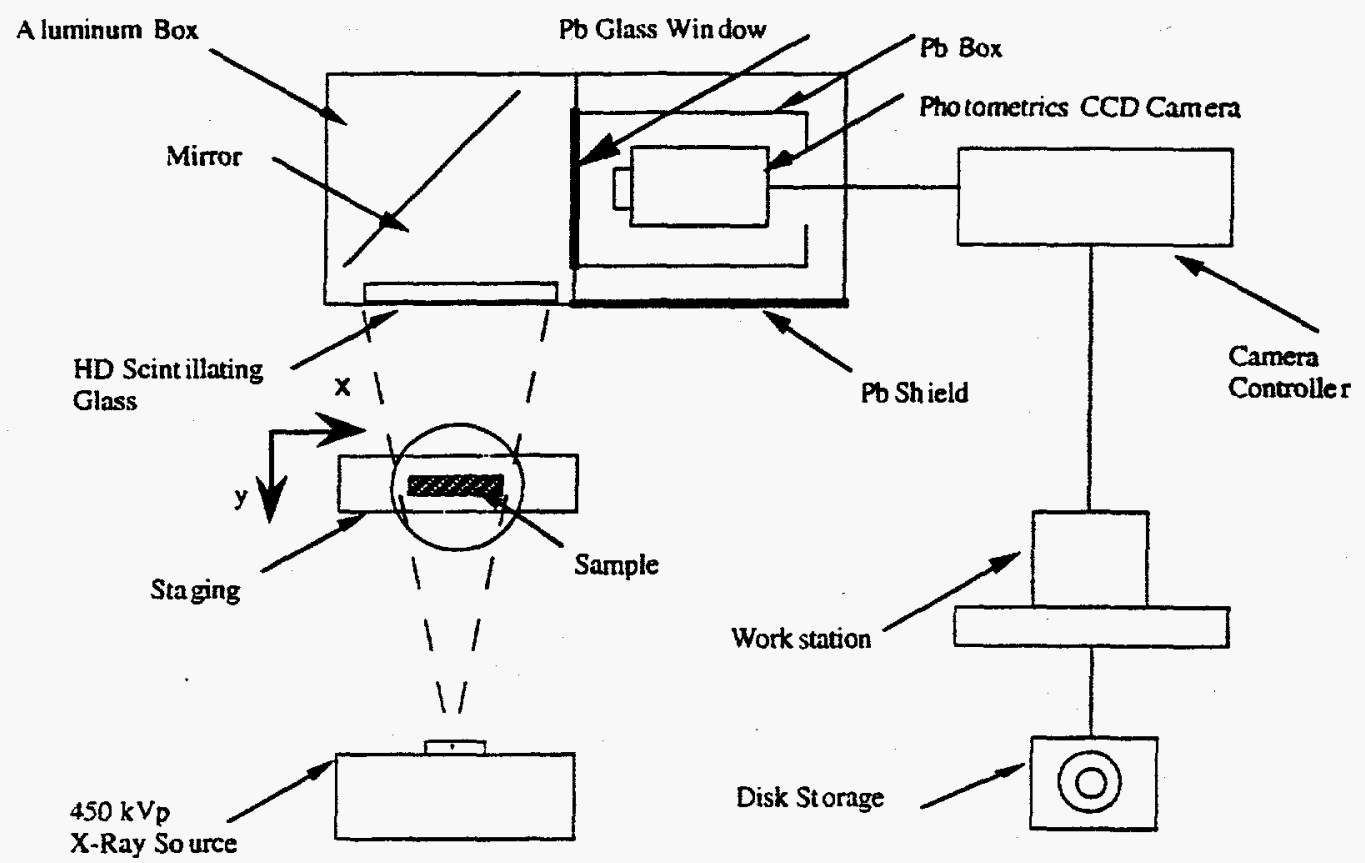

Fig.1 Schematic of the PCAT System.

All the studied samples have a large-aspect ratio (see Table 2), i.e. high value of width to depth in the cross section, which causes a strong variation in the $\mathrm{x}$-ray absorption in the directions along the $\mathrm{x}$ and $\mathrm{y}$ axes. Therefore we decided to scan the specimens in three different configurations (see Table 1):

- Scan-Session A (SS-A)

- Scan-Session B (SS-B)

- Scan-Session C (SS-C)

- Scan-Session D (SS-D) two pieces of the same sample together for SU7/2/P10; one single sample for P35P.20; three different samples together for QIBH.9, P15H.11 and SU7/1/A; one (test only) and two (test and reference) pieces of the same material for QPS1;

to study the influence of the value of the aspect ratio in the reconstruction process for the Carbon-Polymer samples.

The scanner output was preprocessed in order to remove some source of errors that may affect the reconstructed images. We used both the Filtered Backprojection and the Convolution Filtered Backprojection reconstruction algorithms [4], available inside the RECON package at the Lawrence Livermore National Laboratory [5], with a Butterworth filter of order 35 and cutoff frequency 0.45 .

\section{RESULTS AND DISCUSSION}

The data resulting both from DR and CT reconstructed images may be analyzed from different points of view $[4,6,7]$. First of all we can visually compare the DR $x$-ray absorption coefficient or $\mathrm{CT}$ relative $\mathrm{x}$-ray attenuation coefficient variations within each image and from one image to another ${ }^{1}$. Such analysis assume the use of the same display scale and reveais gross anomalies inside the composite samples. The CT data provides the possibility to view internal features within the sample along the three different axes in the 3D space. This allows us to locate several defects in the studied samples, such as cracks, inclusions, voids, delaminations, and to calculate its spatial extent.

\footnotetext{
IThe basic relationship for DR and CT is represented by $I=I_{0} e^{-\mu_{r} l^{\ell}}$ where $: I$ is the photon intensity of the tramsmitted beam; $I_{0}$ is the photon intensity of the incident beam; $\ell$ is the path length; $\mu_{r} l$ is the relative $x$ ray absorption; and $\mu_{r}$ is the relative attenuation coefficient, that is a non linear funcion of the energy, $E$, the density, $\rho$, and the effective atomic number, $Z_{\text {eff }}$.
} 
A more detailed analysis is pertormed by extracting and plotting ID profiles of the data. These protile can spot small vartations within each image. This technique allows to confirm and quantify the anomalies revealed with the previous mentioned analysis and to locate smaller variations between close points. Another detailed technique deals with the entire object or 2D regions belonging to it; this analysis involves the study of the histograms, the mean, the variation and the standard deviation of the CT data set $[6,7]$.

The first two techniques were used for all the scanned samples, the third only for the Graphite-Polyimide one. Here we only describe the results from the SU7/1/A, QIBH.9 and QPS I samples. The results concerning the other samples are given in [3]. Several interesting topics were identified and analyzed in all the considered samples.

\section{Peek and Epoxv Samples}

For the notched QIBH.9 piece, we know from the mechanical model of failure [2] that the ultimate sequence is characterized by the fracture of the $0^{\circ}$ fibers near the hole and large matrix cracks in the adjacent $-45^{\circ}$ plies, noticeable in a typical triangular distribution around the hole. Radiographically we could not determine the number of $-45^{\circ}$ plies damaged. In the CT data, we observed that the triangular damaged area appears in the plies near the outer edge of the sample (see Fig. 2), but is not detectable in the inner plies.

After the loading test the samples were immersed in a zinc-iodide solution to improve the contrast in the Radiographic Films used to study the internal damage due to the static or fatigue test $[2,3]$. Even after the samples were lett inside a water recipient for almost half an hour to eliminate all the remnant of the contrast liquid, we located some strong variations of the attenuation coefficient (up to 6 to 1 with respect to the mean value of the signal inside the sample). This is more likely due to a change in the effective atomic number than in the density value. This result is shown in Fig. 3 for the SU7/1/A sample.

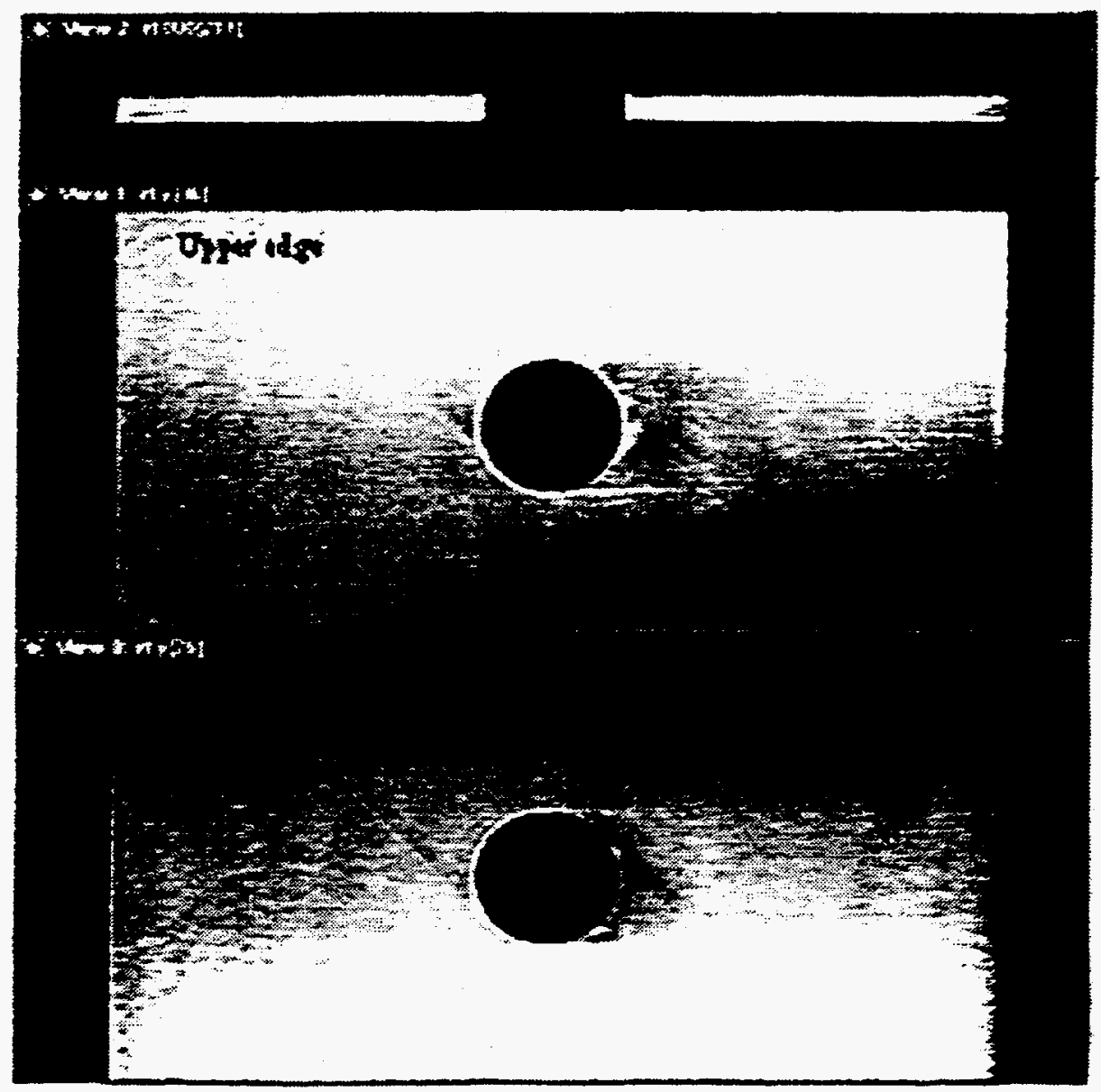

Fig. 2 A reconstructed slice (top) of the QIBH.9 sample with two longitudinal sections (middle and bottom) in the $x-z$ plane. The damaged triangular area around the bole corresponds to the $45^{\circ}$ plies near the outer edge of the sample. 

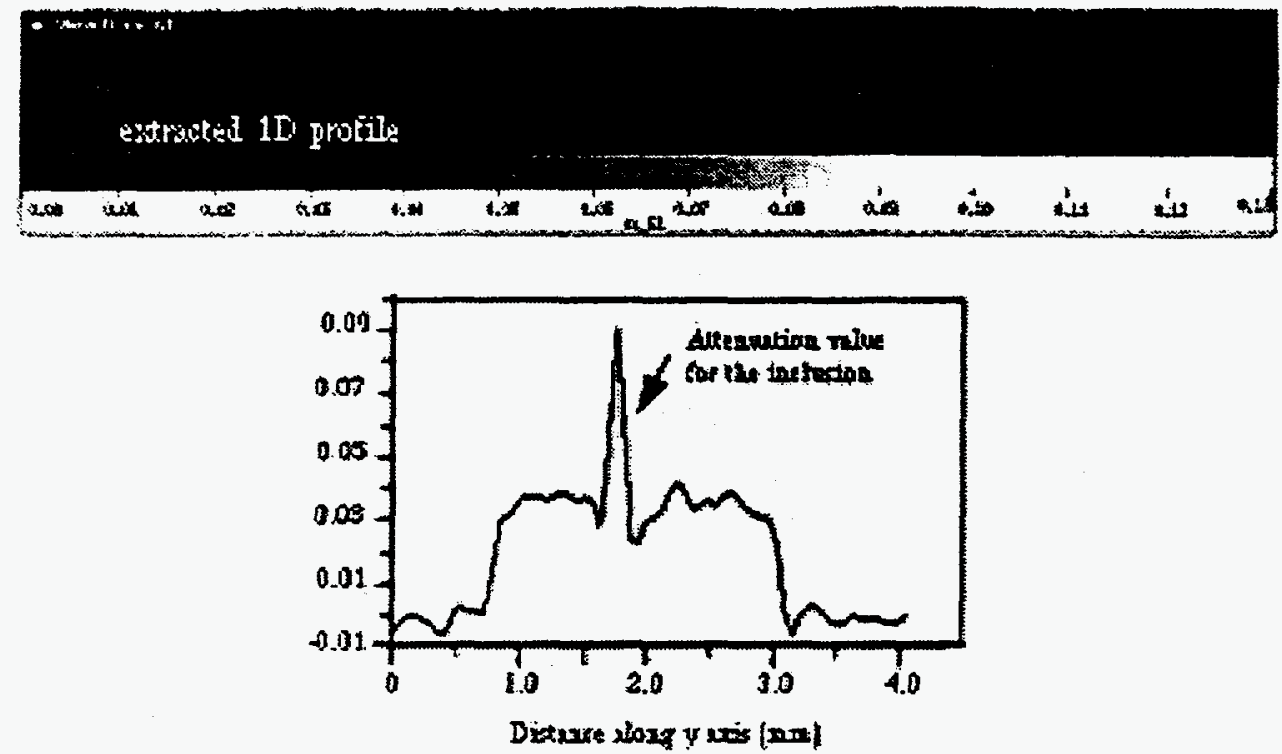

Fig. 3 The SU7/1/A sample: a representative CT cross section (top) and ID profile (bottom) plotted for the line shown in the top CT image.

Graphite-Polvimide Sample

The Digital Radiograph at $90^{\circ}$ reveals two interesting vertical regions (see Fig. 4-left) characterized by a higher value of the relative absorption coefficient, and several low absorption vertical areas; both these regions are most likely due to a variation of the density value. Preliminary analysis revealed that we may correlate the low-density regions with the different ply orientations, see Fig. 4-right. Because all these features appear in the untested sample yet, we may affirm that are due to the manufacturing process.

Comparing the tomograms of a same region with respect to the different loading situations we found some interesting topics :

- a crack, located in the top grip area, appears after the first loading cycle, and seems to be closing in the last considered situation (see Fig. 5);

- an inclusion, identified in the unloaded situation yet, doesn't change both shape and position with the increase of the number of the cycles;

- several delaminations appear near the edges after the last fatigue test, for both the gauge and the grip areas (see Fig. 6-a and b);

- a void was clearly located in the -0.9 Mcycles situation (see Fig. 6-c).
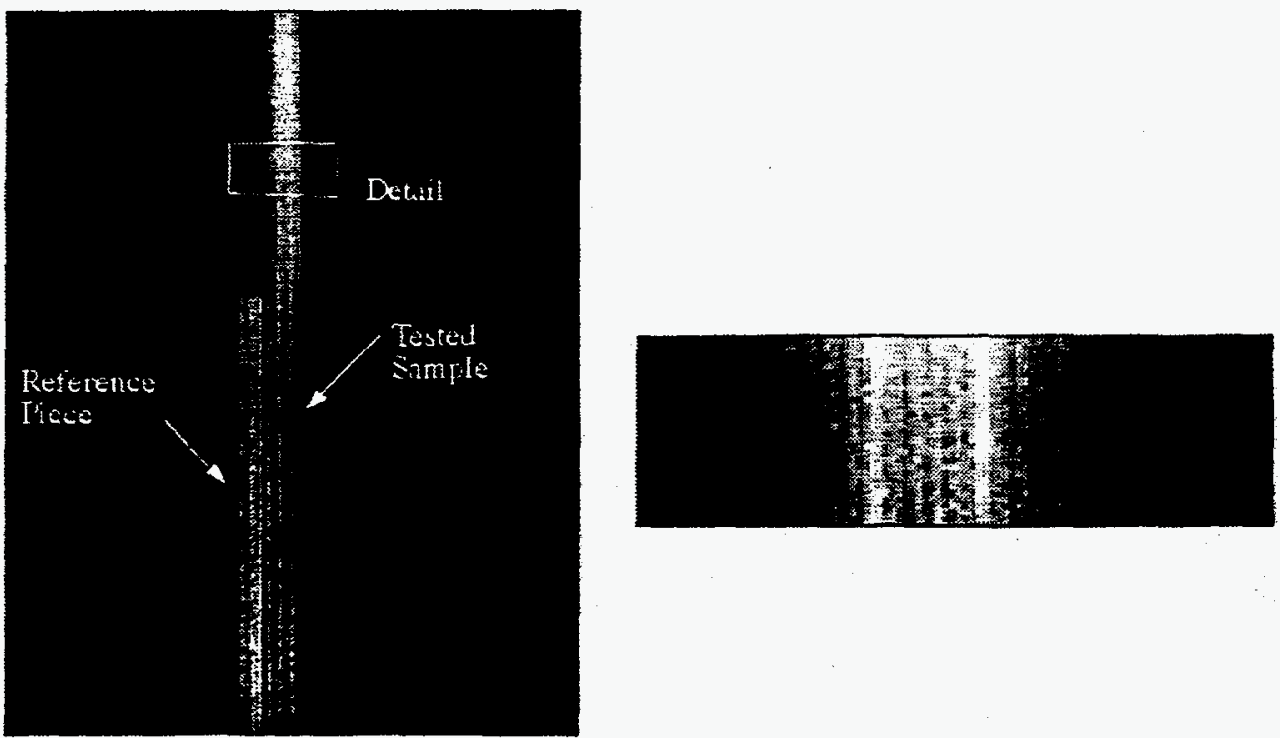

Fig.4 A Digital Radiograph at $90^{\circ}$ (on the left) for the Graphite-Polyimide sample and a detail is shown (on the right) with a magnification factor of 4. 


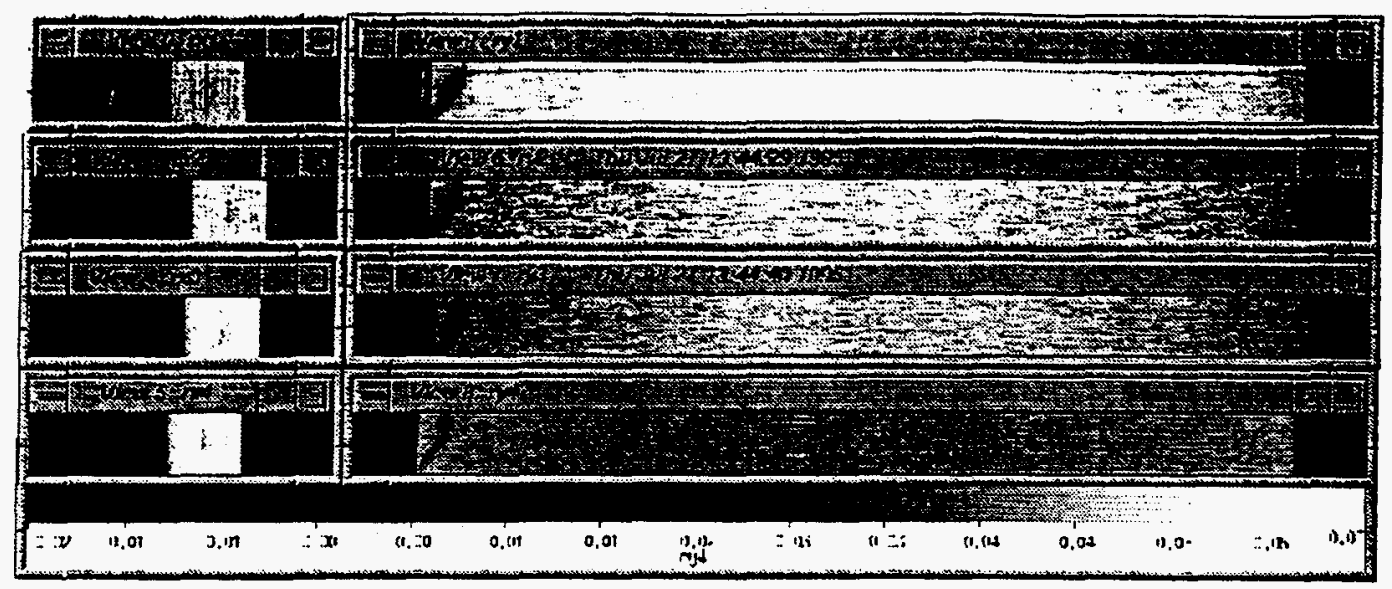

Fig.5 Crack development as a function of the tensile-compression test(the load increases from the top to the bottom).

We were also able to visualize all the different orientations of the fibers in four contiguous sections along the $x-z$ plane, even if the capability of the system doesn't allow us to solve fiber by fiber (whose diameter is about $6 \mu \mathrm{m}$ ).

A histogram (Fig.7-a) related to an extracted region containing an inclusion shows clearly the different peaks corresponding to the background. the scotch tape used for binding the two sample pieces, the reconstructed region inside the sample, the two highdensity regions (see FIg. 4) identified from the beginning in the untested sample and the small inclusion.



a)

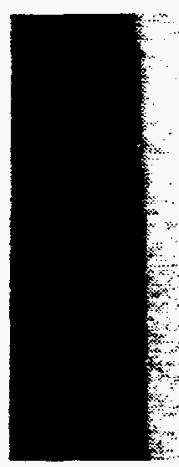

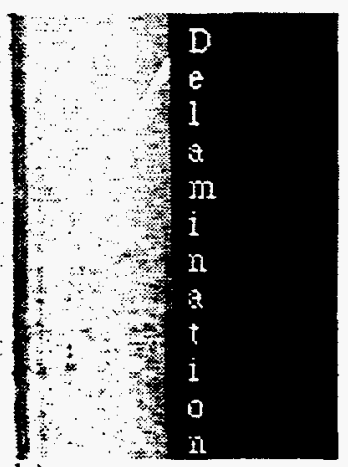

b)

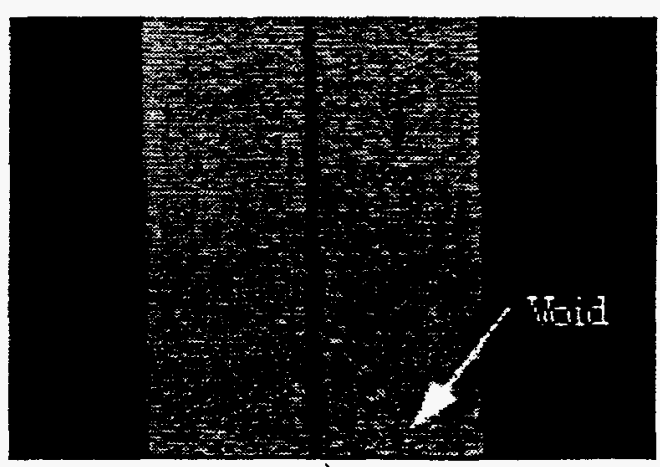

c)

Fig. 6 After the last loading test several defects appear : a) some delaminations in a cross section; b) a transversal section shows the vertical extension for one of the delamination; and c) a void. 


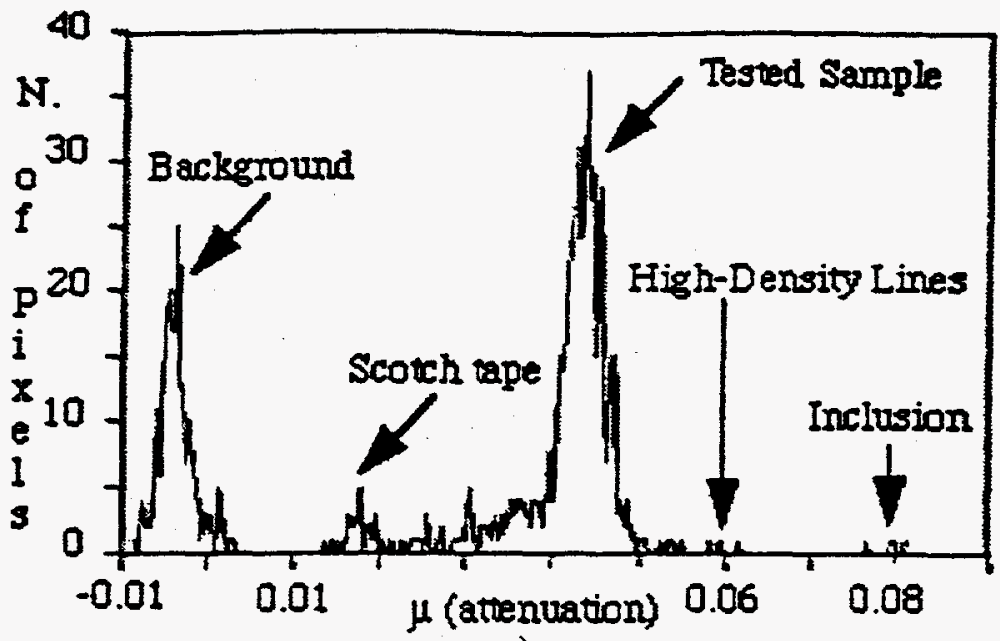

a)

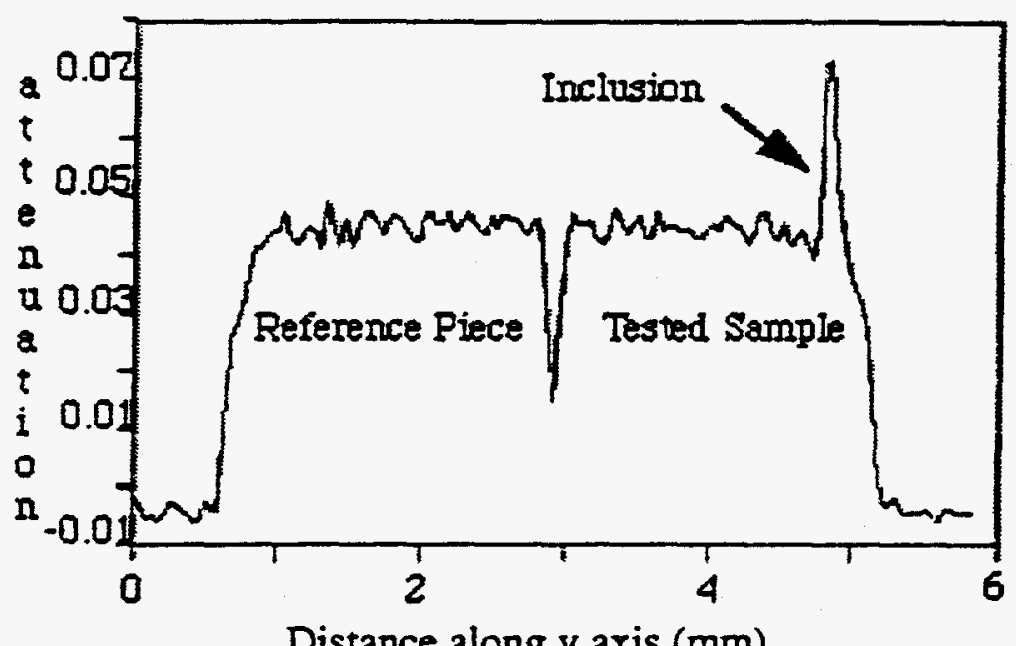

b)

Fig.7 = A histogram (a) and $1 D$ profile (b) characterized by an inclusion .

The attenuation corresponding to the inclusion is shown in Fig.7-b. The ratio between the inclusion and the mean attenuation for the sample is about 1.6. We noticed that the attenuation inside the two samples (reference and test) isn't regular. This fact is probably due to either the different orientation of the fibers in each ply, the matrix or both.

\section{SUMMARY}

In the present work, we studied six different Carion-Polymer Composite samples with different matrix composition, geometric characteristics and static or fatigue loaded to failure. As above mentioned, five of the six considered samples were only studied after the loading test. Their previously unknown situation is a factor of uncertainty with respect to the origin of some observed features inside them.

The study of the Graphite-Polyimide sample allowed us to ascertain some interesting characteristics. First of all we had the possibility to locate from a spatial point of view the defects inside the sample, to establish the moment they appeared, their evolution along the loading test and the relationship between such defects and the mechanical characteristics of the material itself. The use of different investigation techniques permitted us to look at several different aspects of the same phenomena.

One of the main purposes of this study was to determine if the X-ray CT Non Destructive Inspection method can be used to evaluate composite materials characterized by a low-contrast sensitivity between fibers and matrix components without the use of any 
enhancing solution and with fiber dimensions of the order of few microns. We also showed that $\mathrm{x}$-ray data are different in physical characteristic identified and complementary to other

NonDestructive methods. The X-Ray CT results obtained are encouraging with respect to the study of thin Carbon-Polymer Composite Materials.

\section{FUTURE WORK}

Our interest is actually focused on studying the performance of other LLNL CT systems applied on the Carbon-Polymer composites, using linear and area array detectors, different energy values and resolution, to further investigate other methodology in order to study the defects and various features for such materials. An interesting test will be the possibility to compare the results obtained studying the same phenomena with different NonDestructive Techniques (e.g. UT and IR) in order to evaluate the specific capabilities of the proposed method. The development of a CT Scan System in situ for the acquisition in real time both of Digital Radiographs and CT Projections during loading tests using typical load-size sample may represent an important improvement of the proposed method along the way of a more complete knowledge of the behavior of such materials from a spatial and a mechanical point of view.

\section{ACKNOWLEDGMENTS}

The authors would like to thank Dan Schneberk for the useful help and interesting suggestions concerning the computational part of the work, Earl Updike for acquiring the data, and all the other members of the NonDestructive Evaluation Section that have contributed with technical discussion to this work. A special thank is for Jane DeAnda, always willing to help in all the little and big everyday tasks.

\section{REFERENCES}

1. Allen D.H., Groves S.E., Harris C.E., A Cumulative Damage Model for Continuous Fiber Composite Laminates with Matrix Cracking and Interply Delaminations, Composite Material (Eighth Conference).

2. Aymerich F., Priolo P., Danneggiamento in provini angle-ply grafite-peek in presenza di fori, Proc. of XXII Conf. AIAS, Forli Ottobre 1993.

3. Aymerich F., Priolo P., Damage in graphite-peek angle-ply laminates, Proc. of the Seminar "Experimental techniques and design in composite materials"; Cagliari, 22-23 October 1992.

4. Barrett H.H., Swindell W., Radiological Imaging: The Theory of Image Formation, Detection and Processing, vol.1 and 2, New York, Academic Press, 1981.

5. Azevedo S.G., Martz H.E., Skeate M.F., Schneberk D.J., Roberson G.P., Computed Tomography Software and Standards, Lawrence Livermore National Laboratory, Livermore, Calif., UCRL-ID-105132, February, 1990.

6. Martz H.E., Roberson G.P., Skeate M.F., Schneberk D.J., Azevedo S.G., Lynch S., High Explosive (PBX9502) Characterization Using Computerized Tomography, Lawrence Livermore National Laboratory, Livermore, CA,UCRL-ID-103318, February 1990.

7. Weirup D., Martz H.E., Schneberk D.J., Roney T.J., New Production Reactor Target Particle Characterization by Computer Simulation of Computed Tomography Systems, Lawrence Livermore National Laboratory, Livermore, CA, UCRL-UR-114836, August 1993.

8. Savona V., Martz H.E., Study of Carbon-Polymer Composite Samples using an AreaArray CT Scanner, Lawrence Livermore National Laboratory, Livermore, to be published, September 1995. 